\title{
Biomechanical strength dependence on mammalian airway length
}

\author{
Zhao Huang $^{1,2,3 \#}$, Lei Wang ${ }^{1 \#}$, Chen-Xi Zhang ${ }^{1 \#}$, Zhi-Hao Cai ${ }^{4}$, Wen-Hao Liu ${ }^{1}$, Wei-Miao Li ${ }^{1}$, \\ Shu-Gao Ye ${ }^{5 *}$, Xiao-Fei Li ${ }^{1 *}$, Jin-Bo Zhao ${ }^{*}$
}

${ }^{1}$ The Department of Thoracic Surgery, Tangdu Hospital, Air Force Medical University (The Fourth Military Medical University), Xi'an, China; ${ }^{2}$ Department of Cardiothoracic Surgery, Jingling Hospital, Medical School of Nanjing University, Nanjing, China; ${ }^{3}$ The Department of Thoracic Surgery, The 960th PLA Hospital, Ji'nan, China; ${ }^{4}$ State Key Laboratory for Manufacturing Systems Engineering, Xi'an Jiaotong University, Xi'an, China; ${ }^{5}$ Lung Transplant Group, Wuxi People's Hospital Affiliated to Nanjing Medical University, Wuxi, China

Contributions: (I) Conception and design: Z Huang, JB Zhao, L Wang, CX Zhang; (II) Administrative support: JB Zhao, XF Li, SG Ye; (III) Provision of study materials or patients: Z Huang, CX Zhang, SG Ye, JB Zhao; (IV) Collection and assembly of data: Z Huang, L Wang, CX Zhang, WH Liu, WM Li; (V) Data analysis and interpretation: Z Huang, L Wang, ZH Cai, WH Liu, JB Zhao; (VI) Manuscript writing: All authors; (VII) Final approval of manuscript: All authors.

\#These authors contributed equally to this work.

*These authors also contributed equally to this work.

Correspondence to: Jin-Bo Zhao. The Department of Thoracic Surgery, Tangdu Hospital, Air Force Medical University (The Fourth Military Medical University), Xi'an, China. Email: zhaojinbo@aliyun.com; Xiao-Fei Li. The Department of Thoracic Surgery, Tangdu Hospital, Air Force Medical University (The Fourth Military Medical University), Xi’an, China. Email: lxfchest@fmmu.edu.cn; Shu-Gao Ye. Lung Transplant Group, Wuxi People’s Hospital Affiliated to Nanjing Medical University, Wuxi, China. Email: ysg206@hotmail.com.

Background: The trachea is the uppermost respiratory airway element connecting the larynx to the bronchi Airway reconstructions in humans are often developed from animal models but there is limited knowledge comparing tracheal biomechanics between species. We aimed to assess the structure and biomechanics of porcine, canine, caprine and human airways.

Methods: Tracheas from pigs $(n=15)$, goats $(n=9)$ and canines $(n=9)$ were divided into three groups $(4,6$ and 8-ringswhile human left principal brochi $(n=12)$ were divided into two groups (3and-rings). Airway structures were compared using histology and scanning electron microscopy. Biomechanical properties were measured subjecting samples to uniaxial tension and compression, recording the elastic modulus and (tensile and compressive) strengths.

Results: The structures of animal tracheal and human bronchia appeared similar. Biomechanical testing revealed that the elastic modulus of 8-ring tracheas was $1,190.48 \pm 363.68,2,572.00 \pm 608.19$ and $1,771.27 \pm 145.54 \mathrm{kPa}$, for porcine, canine and caprine samples, respectively, while corresponding tensile strengths were $437.63 \pm 191.41,808.38 \pm 223.48$ and $445.76 \pm 44.00 \mathrm{kPa}$. Comparable measures of anteriorposterior (A-P) compression strengths were $7.94 \pm 0.82,7.54 \pm 0.07$ and $8.10 \pm 1.87 \mathrm{~N}$, respectively, whereas lateral compression strengths were $8.75 \pm 0.82,14.55 \pm 2.29$ and $11.12 \pm 0.40 \mathrm{~N}$. Compression testing of human samples showed significant differences $(\mathrm{P}<0.05)$ between the 3-ring $(\mathrm{A}-\mathrm{P}, 1.06 \pm 0.02 \mathrm{~N}$; lateral, $0.55 \pm 0.06 \mathrm{~N})$ and 5-ring groups (A-P, 1.08 $\pm 0.64 \mathrm{~N}$; lateral, $2.32 \pm 1.95 \mathrm{~N}$ ).

Conclusions: The tensile and compressive strengths of mammalian airways show positive correlations with the cartilage ring number (length). On the basis of structural and biomechanical comparisons, porcine, canine and caprine species appear suitable models for the study of airway reconstruction in human.

Keywords: Airway; trachea; bronchi; airway reconstruction; biomechanics

Submitted Sep 24, 2020. Accepted for publication Dec 10, 2020.

doi: $10.21037 /$ jtd-20-2970

View this article at: http://dx.doi.org/10.21037/jtd-20-2970 


\section{Introduction}

The airways are a critical part of the human respiratory system, including the trachea in the uppermost part which connects the larynx to the bronchi of the lungs. Serious obstructions to the trachea caused by stenosis, cancer and trauma can lead to rapid death (1-4). Tracheal resection with end-to-end anastomosis is the routine treatment for tracheal stenosis and tracheal tumors when the lesion is less than $6 \mathrm{~cm}$ in adults $(5,6)$. Other reconstruction techniques are necessary for the treatment of large tracheal defects exceeding $6 \mathrm{~cm}$, including tissue autografts, allografts and tissue-engineered constructs (7-10). Large animal models have proven to be indispensable for developing and applying these surgical procedures.

Some important large animal models for tracheal reconstruction have been described including domestic pigs, goats, dogs and sheep (11-15). However, when selecting an animal model, it is crucial that the model trachea approximates the intended human application in size, histologic, biochemical content and biomechanical characterization Nevertheless, the structural and biomechanical characterization of animal and human airways have not been defined using unified methods. Therefore, developing biomechanical rules that define the size of mammalian airways will enable easier selection of the appropriate animal models and provide more authentic data towards surgical interventions for tracheal grafts.

Thus, the purpose of this study was to define the structural and biomechanical characteristics of porcine, canine, caprine and human airways using unified methods, also aiming to establish cross-species rules of characteristics of mammalian airways. We propose this approach provides a feasible benchmark for implementing models of tracheal tissue grafts and airway reconstruction.

We present the following article in accordance with the ARRIVE reporting checklist (available at http://dx.doi. org/10.21037/jtd-20-2970).

\section{Methods}

\section{Harvesting airway specimens}

The study was conducted in accordance with the Declaration of Helsinki (as revised in 2013) and the National Institute of Health's Guidelines for the Care and Use of Laboratory Animals. The study was approved by the ethics and animal use committee at Tangdu Hospital of the Air Force Medical University (The Fourth Military Medical University) (TDLL-201710-28). Written consent was acquired from each patient before study participation.

Animal tracheas were obtained immediately following euthanasia from market-weight crossbred adult pigs $(n=15$, $100-125 \mathrm{~kg})$, Albas goats $(\mathrm{n}=9,25-28 \mathrm{~kg})$ from a local slaughterhouse. Beagle canines ( $\mathrm{n}=9,25-28 \mathrm{~kg}$ ) were provided by the Experimental Animal Centre of the Air Force Medical University. Human left principal bronchial samples were obtained from organ-donating (brain-dead) patients, without airway problems after obtaining written informed consent from the patient's family members. All human samples were provided by the People's Hospital of Wuxi City, Jiangsu province between 2018 and 2019. Connective tissues surrounding the airways were removed, and the membrane was left intact. All samples were rinsed for $20 \mathrm{~min}$ in physiological saline and frozen in PBS buffer at $-80{ }^{\circ} \mathrm{C}$ for subsequent batch testing. A single freeze thaw cycle has been shown to have negligible effects on tissue sample properties and is a common practice in tissue characterization studies (16-19).

\section{Specimen preparation}

Animal tracheas (porcine $\mathrm{n}=15$, canine $\mathrm{n}=9$, caprine $\mathrm{n}=9$ ) were divided into three groups (4-, 6- and 8-ring groups, respectively). Three 4-ring segments were cut from the proximal, middle and distal portion of each trachea in the 4-ring group respectively. Tracheal length, anteriorposterior (A-P) and lateral tracheal diameters were recorded for each segment. The tracheas of the 6-ring group and 8-ring group were processed as per the 4-ring group. Human bronchi $(\mathrm{n}=12)$ were divided into two groups (3-ring and 5-ring groups, respectively) with each specimen cut from the portion close to the tracheal carina.

\section{Histology}

Tissue samples are taken from tracheas at different positions of the three animal species and the human bronchi, which consists of a single cartilage ring and the inner and outer membranes.

A proportion of samples were fixed for $24 \mathrm{~h}$ in $4 \% \mathrm{w} / \mathrm{v}$ paraformaldehyde at room temperature. After fixation, samples were washed in distilled water, dehydrated in graded alcohol, embedded in paraffin, and cross-sectioned at $4 \mathrm{~mm}$ thickness before staining with haematoxylin and eosin. Other samples were fixed for 30 to 60 minutes in $2.5 \%$ glutaraldehyde, dehydrated with a graded ethanol series $(25-100 \%)$, and critical-point dried using $\mathrm{CO}_{2}$. The dried specimens were mounted on aluminum stubs with 

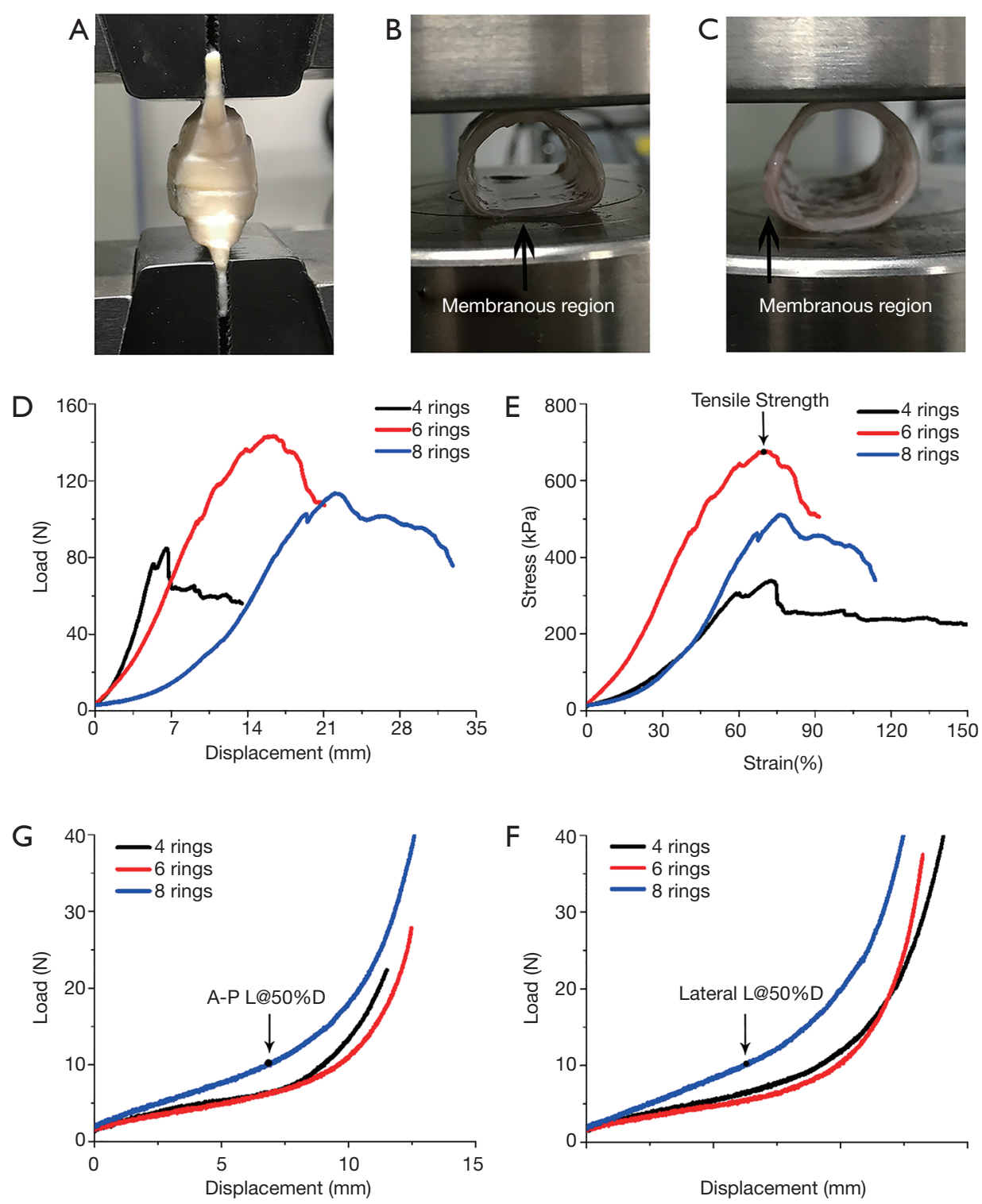

Figure 1 Biomechanical testing: (A) Tensile testing; (B) A-P radial compression testing; (C) lateral radial compression testing; (D) LoadDisplacement curve of tensile testing; (E) stress-strain curve of tensile testing; (F) Load-Displacement curve of A-P radial compression; (G) Load-Displacement curve of lateral radial compression.

carbon adhesive tabs and sputter coated with gold palladium. Samples were subsequently imaged by scanning electron microscopy (SEM) (S-4800; HITACHI Inc., Tokyo, Japan) with images recorded at 30 to $5,000 \times$ magnification.

\section{Biomechanical testing}

All mechanical tests were carried out using a multi- functional static testing machine (CMT4304, 1N-30kN; SANS/MTS, Shanghai, China) with the force-displacement data recorded (Figure 1). Tensile testing was performed on all proximal trachea specimens. Anterior-posterior (A-P) radial compression testing tensile testing was performed on all middle trachea specimens and half of the bronchus specimens from the 3-ring and 5-ring groups. The lateral radial compression testing was performed on all distal 
trachea specimens and half of the bronchus specimens from the 3-ring group and 5-ring groups.

\section{Tensile testing}

The proximal and distal ends of the tracheal specimen were clamped on the fixture of the test machine. The uniaxial tensile testing was performed with a $5 \mathrm{~mm} / \mathrm{min}$ strain rate until sample failure or stress relaxation by applying a constant strain (Figure 1A). The force-displacement data (Figure 1D) recorded by the tensile machine were converted to stress-strain data using the following equations:

$$
\begin{aligned}
& \varepsilon=\Delta L / L_{0} \\
& \sigma=F / A_{0}
\end{aligned}
$$

Where $\Delta \mathrm{L}$ and $\mathrm{F}$ represent the displacement and tensile force, respectively; $\sigma$ represents stress; $\varepsilon$ represents strain; and finally, $\mathrm{A}_{0}$ and $\mathrm{L}_{0}$ represent the initial cross section area and length of the specimen, respectively. The inner and outer rings of the trachea in the tensile test are approximately circular, and the cross-sectional area is $\pi\left(R^{2}-r^{2}\right)$. After multiple measurements, the average value is obtained, and the original length of the trachea is obtained by averaging multiple measurements.

In the stress-strain curve (Figure $1 E$ ), the strain of the trachea is in the elastic phase from $20 \%$ to $50 \%$, which approximates a straight line. The data was fitted linearly with the slope of the straight line being the elastic modulus of the trachea. The elastic modulus (E), which defines the relationship between stress $(\sigma)$ and strain $(\varepsilon)$ in a linear elastic material, can be calculated using the following equation:

$$
E=\sigma / \varepsilon
$$

The stress value at the highest point of the strain is recorded as its tensile strength.

\section{Compression testing}

In the A-P radial compression tests, the membrane area of the tracheal section was clamped down to the fixture of the testing machine, and a $1.5 \mathrm{~N}$ preload was applied. The compression testing was performed at a displacement of $5 \mathrm{~mm} / \mathrm{min}$. The compression machine depicted the Load-Displacement curve (Figure $1 F$ ). In the lateral radial compression test, the membrane area of the tracheal section is clamped and fixed to the fixture of the testing machine perpendicular to the horizontal direction, and a $1.5 \mathrm{~N}$ lateral preload is given, and the lateral radial compression test performed with a displacement of $5 \mathrm{~mm} / \mathrm{min}$. The compression machine depicts the Load-Displacement curve (Figure 1G). Regarding the Load-Displacement curve, the value of the recording load is the compression strength (L@50\%D) when the displacement reaches $50 \%$ of the original length of the trachea.

\section{Statistical analysis}

All statistical analyses were performed using the SPSS v24.0 software (SPSS, Chicago, IL, USA) and all linear fitting performed using the origin Pro v9.0 software (Originlab, Northampton, MA, USA).

The data were first checked for normal distribution using the Shapiro-Wilk test, which resulted in $\mathrm{P}$ values greater than 0.05 (The null-hypothesis of this test is that the population is normally distributed). Thereafter, one-way analysis of variance (AVONA) compared the experimental results obtained from the tracheal samples with respect to the cartilage ring number, with the significance level set at 0.05 . All data were presented as means $\pm \mathrm{SD}$.

\section{Results}

\section{Histology}

H\&E staining and SEM of trachea cross-sections revealed a complex multilayer architecture consisting of fibrous tissue layers surrounding inner cartilaginous rings and an inner epithelial layer (Figure 2). The cartilage lacuna and chondrocytes were visible inside of cartilaginous ring cross sections (Figure 2A,C,E). Additional SEM imaging also revealed that the inner and outer layers of the tracheal cartilage ring of different species were wrapped with connective tissue composed of elastic fibers. The cartilage matrix fibers grew from the center to the sides with the thick center and narrow end. Furthermore, there were cartilage lacuna and chondrocytes in the cartilage matrix (Figure 2B,D,F).

\section{Biomechanical testing}

Prior to biomechanical testing, the scale of animal tracheal samples were measured and analyzed (Table S1) in order to ensure that the animal tracheal samples from different groups were uniform cylindrical tubes of defined length. These parameters were then used to conduct biomechanical 
A
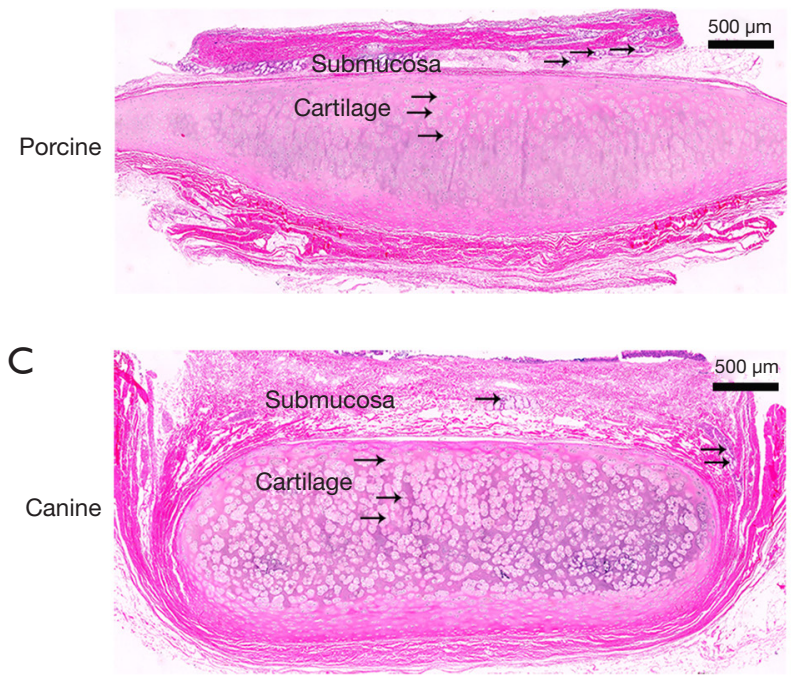

$\mathrm{E}$

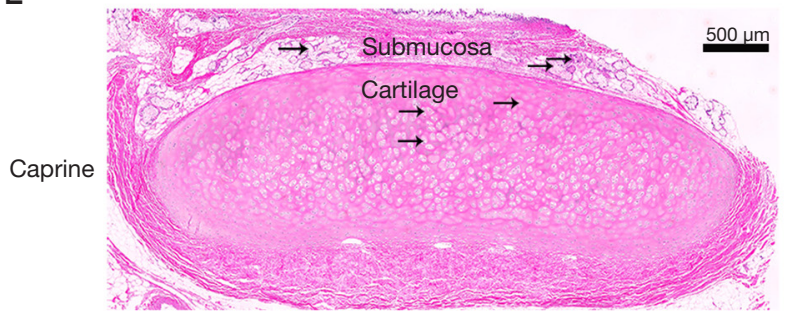

B
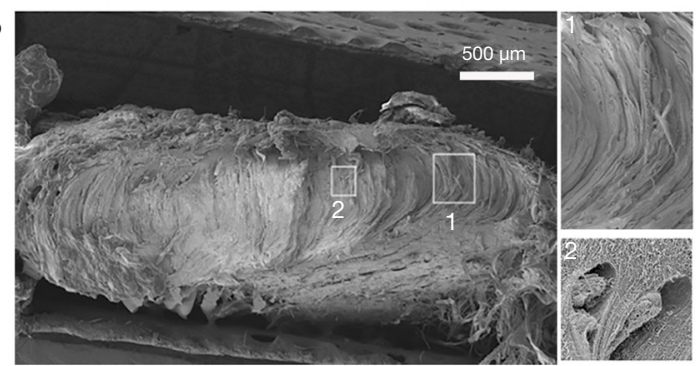

D
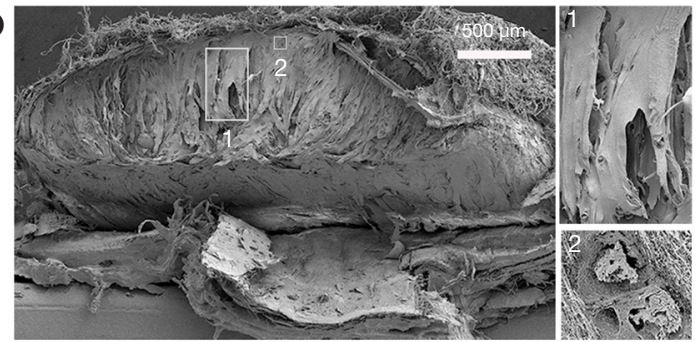

$\mathrm{F}$

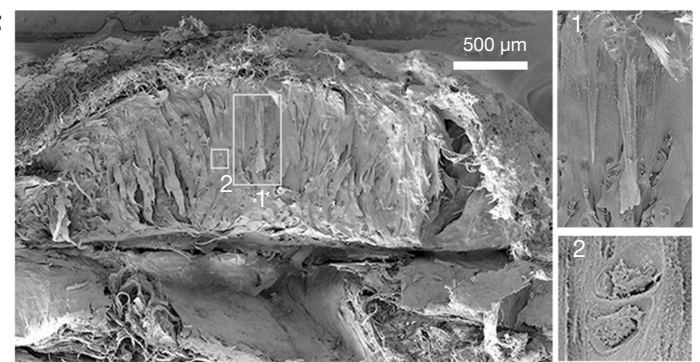

Figure 2 Morphological observation of different species of tracheal cross section: (A) HE staining results of porcine tracheal cross section; (B) scanning electron microscope (SEM) results of porcine tracheal cross section; (C) HE staining results of canine tracheal cross section; (D) SEM results of canine tracheal cross section; (E) HE staining results of caprine tracheal cross section; (F) SEM results of caprine tracheal cross section. Arrows in submucosa pointing to submucosa glands and adipocytes; arrows in cartilage pointing to cartilage lacuna and chondrocytes.

tests (Tensile and Compression) on the animal samples. The results were shown in Table 1 and Figure $3 A-D$. Besides, the statistical analyses (One-Way ANOVA) were presented in Tables $\mathrm{S} 2$ and $\mathrm{S} 3$ and Figure $3 \mathrm{E}-\mathrm{H}$.

\section{Tensile testing}

In tensile testing, increasing numbers of rings increases both the elastic modulus and tensile strength. The elastic modulus of the 8-ring group for porcine, canine and caprine tracheas was $1,190.48 \pm 363.68,2,572.00 \pm 608.19$ and $1,771.27 \pm 145.54 \mathrm{kPa}$ respectively, while the corresponding tensile strength measures were $437.63 \pm 191.41$, $808.38 \pm 223.48$ and $445.76 \pm 44.00 \mathrm{kPa}$, respectively (all data in Table 1). There was no consistent statistical differences in the tracheal tensile elastic modulus among the three groups of different species (porcine, $\mathrm{P}>0.05$; Canine and Goat, $\mathrm{P}<0.05$ ) (Figure $3 A$ ). Neither were there significant statistical differences in tensile strength between the different groups $(\mathrm{P}>0.05)$ (Figure 3B). However, there was a statistically significant positive correlation identified between the number of rings and the tracheal elastic modulus and tensile strength $\left(\mathrm{R}^{2}>0.8\right)$ (Figure $\left.3 E, F\right)$. The latter finding may be related to the uneven distribution of cartilage ring growth in different segments of the trachea.

\section{Compression testing}

During compression testing, when the tracheal sections are compressed down to $50 \%$ original length, they are not crushed, and can be restored to their original shape while maintaining a good structure. The A-P compression strengths of the 8-ring group for porcine, canine and caprine tracheas was $7.94 \pm 0.82,7.54 \pm 0.07$ and $8.10 \pm 1.87$, respectively, while the corresponding lateral compression strengths were $8.75 \pm 0.82,14.55 \pm 2.29$ and $11.12 \pm 0.40$, respectively (all data 
Table 1 Biomechanical characteristic of animal tracheas

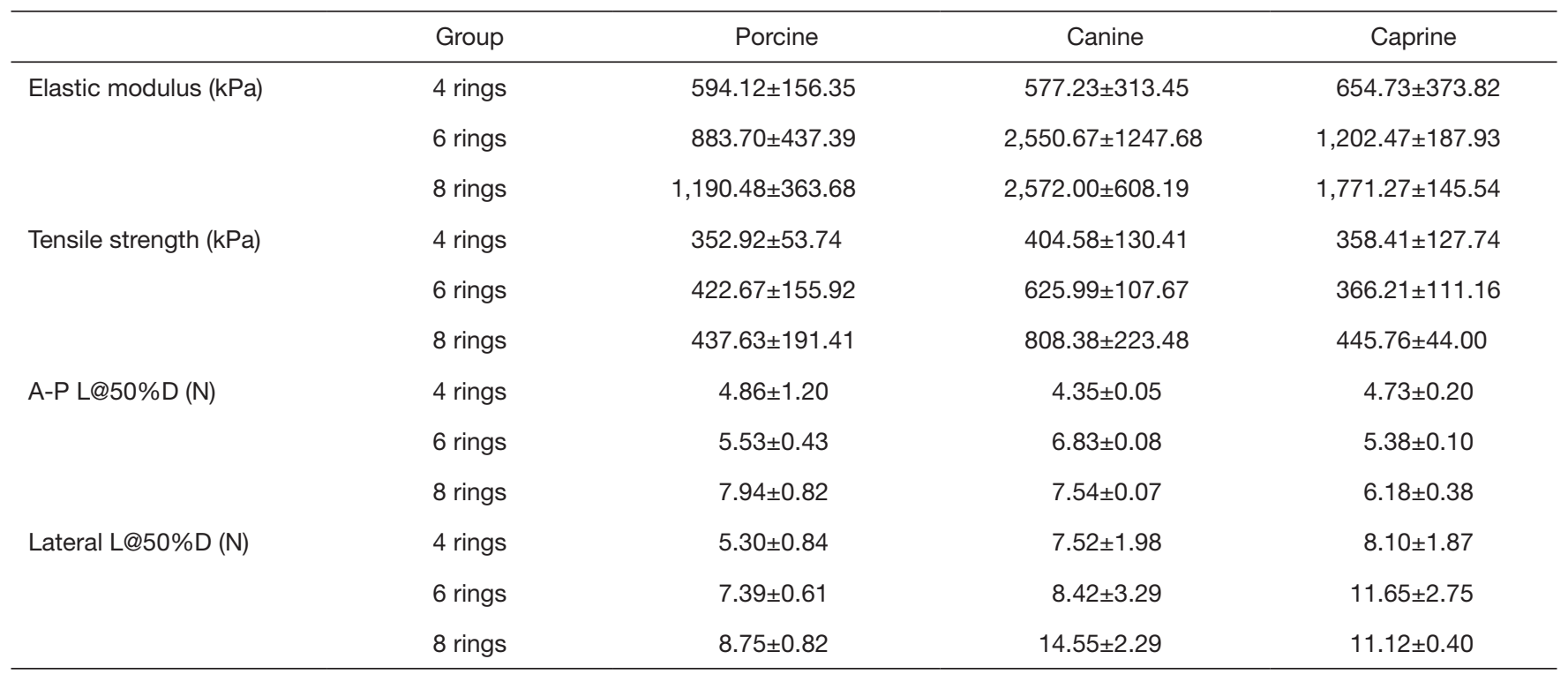

A-P, anterior-posterior; L@50\%D, load at the displacement reaches the $50 \%$ original length of trachea.

A
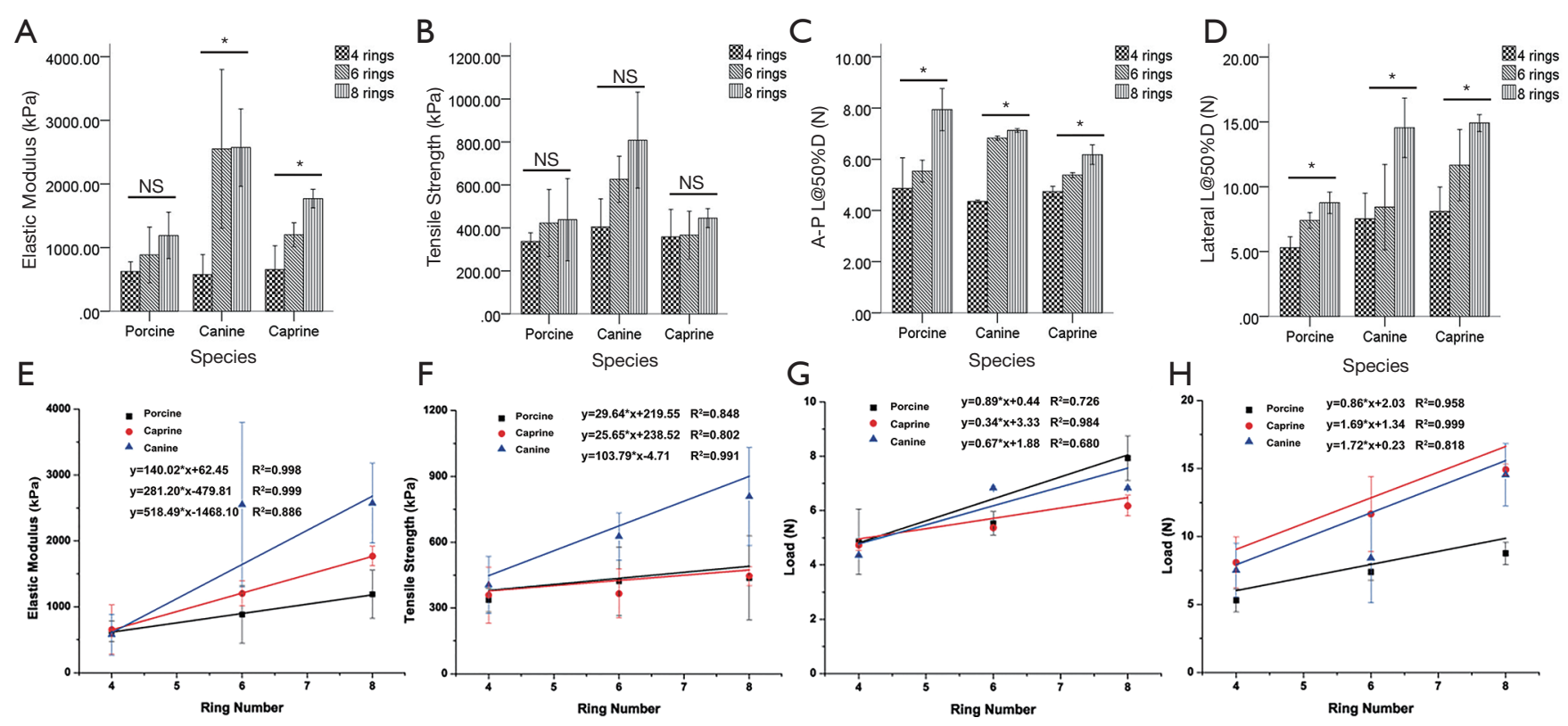

Figure 3 Statistical analysis of biomechanical parameters and linear fitting: (A) comparison of tensile elastic modulus among different groups; (B) comparison of tensile strength among different groups; (C) comparison of A-P compression strengths among different groups; (D) comparison of lateral compression strengths among different groups; (E) linear fitting of elastic modulus and ring number; (F) linear fitting of tensile strength and ring number; $(\mathrm{G})$ Linear fitting of A-P compression strengths and ring number; (H) linear fitting of lateral compression strengths and ring number. ${ }^{*} \mathrm{P} \leq 0.05$; NS: no significance $(\mathrm{P}>0.05)$.

in Table 1). Statistical analyses revealed significant statistical differences $(\mathrm{P}<0.05)$ among the $\mathrm{A}-\mathrm{P}$ radial compression strengths of different species (Figure 3C). Linear fitting results indicated that the A-P and lateral compression strengths of the tracheas were positively correlated with the number of rings (A-P compression $\mathrm{R}^{2}>0.5$; lateral compression $\mathrm{R}^{2}>0.8$ ) (Figure 3G,H) although the correlation strength with lateral compression was stronger than A-P compression. 

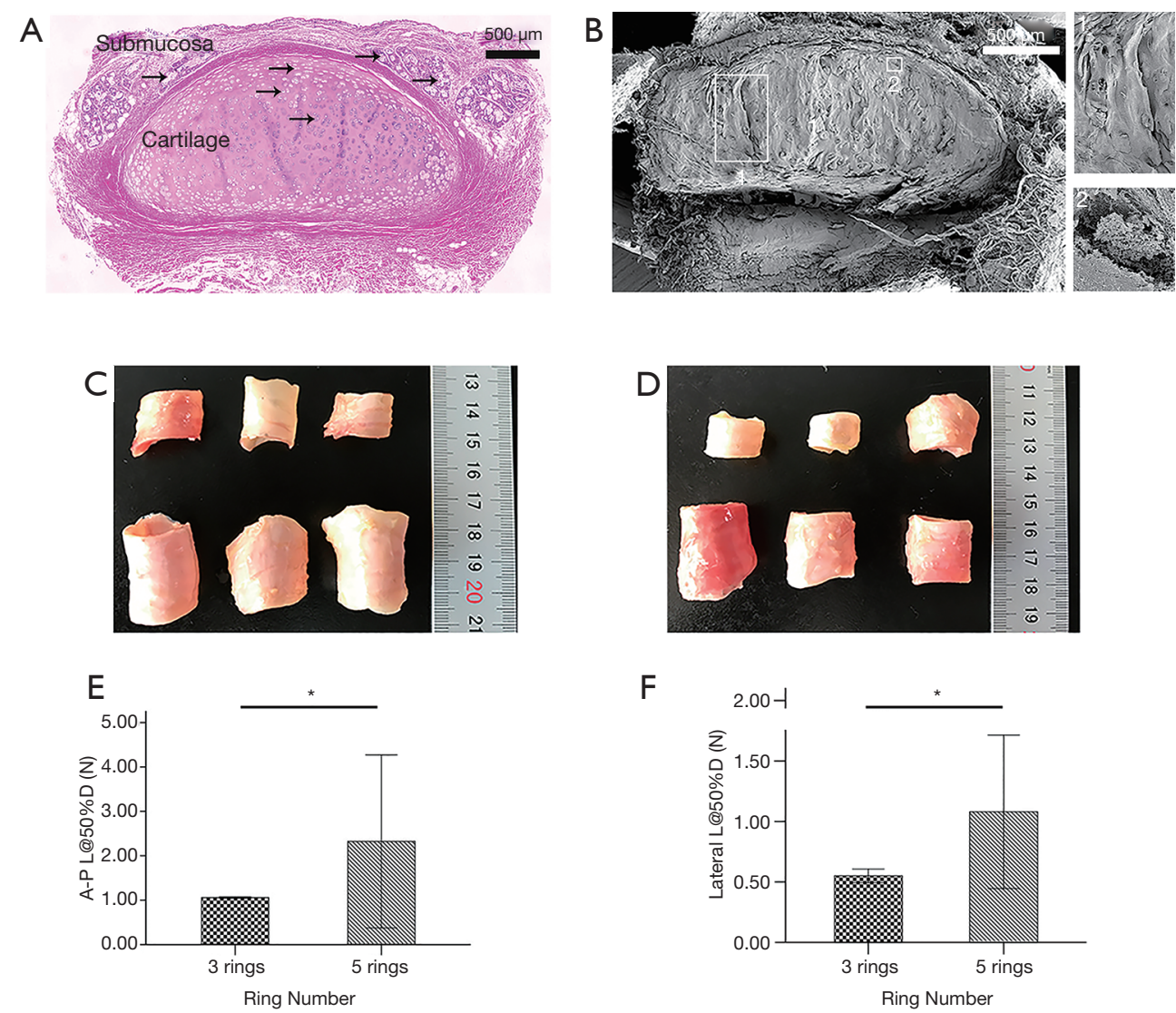

Figure 4 Results of tests on human bronchial specimens: (A,B) the histology and SEM of human bronchial cross section (A: HE staining); (C,D) pictures of human left principal bronchial specimens performed in A-P and lateral compression tests; (E) comparison of A-P compression strengths between 3-ring group and 5-ring group; (F) comparison of lateral compression strengths between 3-ring group and 5-ring group. * $\mathrm{P}<0.05$.

\section{Mechanical tests on buman samples}

The histology and SEM of human bronchi demonstrated a complex multilayer architecture (Figure $4 A-D$ ) that is identical to animal tracheas. The results of A-P and lateral compression testing performed on human bronchial specimens showed that with increasing number of rings, the A-P compression strength and lateral compression strength both increased. Indeed, for compression testing there were statistically significant differences $(\mathrm{P}<0.05)$ between the 3-ring (A-P, $1.06 \pm 0.02 \mathrm{~N}$; lateral, $0.55 \pm 0.06 \mathrm{~N}$ ) and 5-ring groups (A-P, $1.08 \pm 0.64 \mathrm{~N}$; lateral, $2.32 \pm 1.95 \mathrm{~N}$ ) (Figure 4E,F).

\section{Discussion}

The tracheal structure of larger mammals such as the pig, $\mathrm{dog}$ and goat is more similar to humans in terms of size, morphology, and physiology compared to smaller laboratory animals such as rodents (8). Tracheal reconstruction studies on large animals may therefore represent more faithful models for developing clinical approaches prior to implementation in humans.

In recent years, an increasing number of tracheal reconstruction studies on large animals and some clinical reports have suggested an urgent need to better understand the mechanical properties of the native airways of human and animals $(7,11,20-22)$. In this study, we performed mechanical tests using unified methods to assess and compare large animal species against human airways. A mass of detailed and objective data was obtained with the notable finding that mechanical characteristics positively correlate with ring number (length).

The tensile characteristics of animal tracheas have not previously been investigated thoroughly and many reported studies have employed homogenized rather than intact tracheas $(18,19,23)$. Here we observed that the tensile characteristics (elastic modulus and tensile strength) of animal tracheas were positively correlated with the number of tracheal cartilage rings (Figure $3 A, B, E, F$ ). This highly informative finding provides a clear lesson for all future tracheal reconstruction research 
where it cannot be assumed that the trachea is a homogeneous, readily substituted organ between species.

Many efforts have been put into defining the compressive characteristics of animal and human airways although usually in the context of a single species. However, this presents major difficulties in comparing and normalizing key mechanical parameters amongst species (16-19,23-25). In our study, we performed two directional (A-P and lateral) compression tests on three kinds of large animal tracheas versus human bronchi and defined the compressive characteristics of airways in detail. These results indicated that the compressive characteristics (A-P and Lateral L@50\%D) of animal tracheas are positively correlated with the number of tracheal cartilage rings $(\mathrm{P}<0.05)$ (Figure 3C,D,G,H). According to the mechanical tests on the human samples, the compression strength (A-P and lateral) of the 5-ring group was significantly increased compared to that of the 3-ring group $(\mathrm{P}<0.05)$ (Figure $4 E, F)$. Therefore, similar to animal airways, the compression strength of human airways may also be positively correlated with airway length. However, we note the difficulties in obtaining human tracheas, and caution the limitations of our findings where data would be better collected using human main tracheas. Nonetheless, we have demonstrated a feasible approach for defining the biomechanical characteristics of tracheas in a variety of species.

Our study obtained the detailed structural and biomechanical data of large animals (sus, canis and capra) and human airways. It was also found that both the tensile and compressive strengths had significant positive correlations with the cartilage ring number (length) of mammal airways. These results propose that for studies of airway reconstruction, these three large animals all represent good models. Notwithstanding this conclusion, in the study of human airway reconstruction, especially for the process of tissue engineering, the effect of tracheal length (cartilage ring number) on mechanical properties should be carefully considered and evaluated.

In conclusion, our findings provide a reliable basis for selecting appropriate animal models for airway reconstruction and the preparation of substitute airways. Moreover, the basic mechanical information detailed in our results can be used as reference information for all manner of clinicians and basic researchers in this field including applications in tissue engineering, 3D printing and airway stent design.

\section{Acknowledgments}

The authors thank PhD. Zhao-Xiang Chen and Pro. Jian-
Kang He for his expertise and assistance with mechanical testing and mounting apparatus construction. In addition, the authors acknowledge the assistance of EditSprings language editing service (www.editsprings.com) in revising the manuscript for publication.

Funding: This work was supported by the project of Youth Science and Technology New Star in Shaanxi Province (2018KJXX-051) (JBZ); and the funding for Young Scientist from Tangdu Hospital (2019) (JBZ).

\section{Footnote}

Reporting Checklist: The authors have completed the ARRIVE reporting checklist. Available at http://dx.doi. org/10.21037/jtd-20-2970

Data Sharing Statement: Available at http://dx.doi. org/10.21037/jtd-20-2970

Conflicts of Interest: All authors have completed the ICMJE uniform disclosure form (available at http://dx.doi. org/10.21037/jtd-20-2970). The authors have no conflicts of interest to declare.

Ethical Statement: The authors are accountable for all aspects of the work in ensuring that questions related to the accuracy or integrity of any part of the work are appropriately investigated and resolved. The study was conducted in accordance with the Declaration of Helsinki (as revised in 2013) and the National Institute of Health's Guidelines for the Care and Use of Laboratory Animals. The study was approved by the ethics and animal use committee at Tangdu Hospital of the Air Force Medical University (The Fourth Military Medical University) (TDLL-201710-28). Written consent was acquired from each patient before study participation.

Open Access Statement: This is an Open Access article distributed in accordance with the Creative Commons Attribution-NonCommercial-NoDerivs 4.0 International License (CC BY-NC-ND 4.0), which permits the noncommercial replication and distribution of the article with the strict proviso that no changes or edits are made and the original work is properly cited (including links to both the formal publication through the relevant DOI and the license). See: https://creativecommons.org/licenses/by-nc$\mathrm{nd} / 4.0 /$. 


\section{References}

1. Huston B, Froloff V, Mills K, et al. Adenoid Cystic Carcinoma of the Trachea Resulting in Fatal Asphyxia. J Forensic Sci 2017;62:244-6.

2. Chung SR, Yang JH, Jun TG, et al. Clinical outcomes of slide tracheoplasty in congenital tracheal stenosis. Eur J Cardiothorac Surg 2015;47:537-42.

3. Wicky S, Wintermark M, Schnyder P, et al. Imaging of blunt chest trauma. Eur Radiol 2000;10:1524-38.

4. Deslée G, Brichet A, Lebuffe G, et al. Obstructive fibrinous tracheal pseudomembrane. A potentially fatal complication of tracheal intubation. Am J Respir Crit Care Med 2000;162:1169-71.

5. Pfeiffer M, Cohn JE, Pascasio JM, et al. Treatment of an obstructive, recurrent, syncytial myoepithelioma of the trachea with tracheal resection and reconstruction. Int J Pediatr Otorhinolaryngol 2018;109:85-8.

6. Mathisen D. Distal Tracheal Resection and Reconstruction: State of the Art and Lessons Learned. Thorac Surg Clin 2018;28:199-210.

7. Martinod E, Chouahnia K, Radu DM, et al. Feasibility of Bioengineered Tracheal and Bronchial Reconstruction Using Stented Aortic Matrices. JAMA 2018;319:2212-22.

8. Goh CS, Joethy JV, Tan BK, et al. Large animal models for long-segment tracheal reconstruction: a systematic review. J Surg Res 2018;231:140-53.

9. Abouarab AA, Elsayed HH, Elkhayat H, et al. Current Solutions for Long-Segment Tracheal Reconstruction. Ann Thorac Cardiovasc Surg 2017;23:66-75.

10. de Jong AL, Park AH, Raveh E, et al. Comparison of thyroid, auricular, and costal cartilage donor sites for laryngotracheal reconstruction in an animal model. Arch Otolaryngol Head Neck Surg 2000;126:49-53.

11. Xia D, Jin D, Wang Q, et al. Tissue-engineered trachea from a 3D-printed scaffold enhances whole-segment tracheal repair in a goat model. J Tissue Eng Regen Med 2019;13:694-703.

12. Al-Ayoubi AM, Rehmani SS, Sinclair CF, et al. Reconstruction of Anterior Tracheal Defects Using a Bioengineered Graft in a Porcine Model. Ann Thorac Surg 2017;103:381-9.

13. Shin YS, Choi JW, Park JK, et al. Tissue-engineered tracheal reconstruction using mesenchymal stem cells seeded on a porcine cartilage powder scaffold. Ann Biomed Eng 2015;43:1003-13.

14. Peng C, Ma J, Cheema M, et al. Application of a bioengineered composite neotrachea in a dog model. J
Surg Res 2015;194:638-43.

15. Wood MW, Murphy SV, Feng X, et al. Tracheal reconstruction in a canine model. Otolaryngol Head Neck Surg 2014;150:428-433.

16. Hoffman B, Martin M, Brown BN, et al. Biomechanical and biochemical characterization of porcine tracheal cartilage. Laryngoscope 2016;126:E325-31.

17. Jones MC, Rueggeberg FA, Cunningham AJ, et al. Biomechanical changes from long-term freezer storage and cellular reduction of tracheal scaffoldings. Laryngoscope 2015;125:E16-22.

18. Jones MC, Rueggeberg FA, Faircloth HA, et al. Defining the biomechanical properties of the rabbit trachea. Laryngoscope 2014;124:2352-8.

19. Shi HC, Deng WJ, Pei C, et al. Biomechanical properties of adult-excised porcine trachea for tracheal xenotransplantation. Xenotransplantation 2009;16:181-6.

20. Kaye R, Goldstein T, Grande DA, et al. A 3-dimensional bioprinted tracheal segment implant pilot study: Rabbit tracheal resection with graft implantation. Int J Pediatr Otorhinolaryngol 2019;117:175-8.

21. Li D, Yin Z, Liu Y, et al. Regeneration of trachea graft with cartilage support, vascularization, and epithelization. Acta Biomater 2019;89:206-16.

22. Gao B, Jing H, Gao M, et al. Long-segmental tracheal reconstruction in rabbits with pedicled Tissue-engineered trachea based on a 3D-printed scaffold. Acta Biomater 2019;97:177-86.

23. Lee JS, Park J, Shin DA, et al. Characterization of the biomechanical properties of canine trachea using a customized 3D-printed apparatus. Auris Nasus Larynx 2019;46:407-16.

24. Sun F, Pan S, Shi HC, et al. Structural integrity, immunogenicity and biomechanical evaluation of rabbit decelluarized tracheal matrix. J Biomed Mater Res A 2015;103:1509-19.

25. Trabelsi O, del Palomar AP, López-Villalobos JL, Ginel A, Doblaré M. Experimental characterization and constitutive modeling of the mechanical behavior of the human trachea. Med Eng Phys 2010;32:76-82.

Cite this article as: Huang Z, Wang L, Zhang CX, Cai ZH, Liu WH, Li WM, Ye SG, Li XF, Zhao JB. Biomechanical strength dependence on mammalian airway length. J Thorac Dis 2021;13(2):918-926. doi: 10.21037/jtd-20-2970 


\section{Supplementary}

Table S1 Scale of animal tracheal samples

\begin{tabular}{|c|c|c|c|c|c|c|c|c|c|c|c|}
\hline Species & Group & $\begin{array}{l}\text { Length } \\
\text { (cm) }\end{array}$ & $\mathrm{P}$ value & $\begin{array}{c}\text { A-P inner } \\
\text { diameter }(\mathrm{cm})\end{array}$ & $P$ value & $\begin{array}{l}\text { A-P external } \\
\text { diameter } \\
(\mathrm{cm})\end{array}$ & $P$ value & $\begin{array}{l}\text { Lateral inner } \\
\text { diameter } \\
\text { (cm) }\end{array}$ & $P$ value & $\begin{array}{l}\text { Lateral } \\
\text { external } \\
\text { diameter } \\
(\mathrm{cm})\end{array}$ & $P$ value \\
\hline \multirow[t]{2}{*}{ Porcine } & 4 rings & $2.18 \pm 0.23$ & $<0.001^{*}$ & $1.70 \pm 0.22$ & 0.389 & $2.36 \pm 0.1$ & 0.096 & $1.92 \pm 0.16$ & 0.549 & $2.48 \pm 0.08$ & 0.382 \\
\hline & 6 rings & $3.09 \pm 0.18$ & & $1.45 \pm 0.12$ & & $2.15 \pm 0.13$ & & $1.85 \pm 0.17$ & & $2.32 \pm 0.16$ & \\
\hline \multirow[t]{3}{*}{ Canine } & 4 rings & $2.00 \pm 0.10$ & $0.012^{*}$ & $1.40 \pm 0.20$ & 0.988 & $1.88 \pm 0.3$ & 1.000 & $1.83 \pm 0.13$ & 0.204 & $2.12 \pm 0.20$ & 0.079 \\
\hline & 6 rings & $3.17 \pm 0.38$ & & $1.42 \pm 0.16$ & & $2.13 \pm 0.84$ & & $1.98 \pm 0.33$ & & $2.60 \pm 0.35$ & \\
\hline & 8 rings & $3.70 \pm 0.72$ & & $1.42 \pm 0.03$ & & $1.88 \pm 0.20$ & & $2.23 \pm 0.23$ & & $2.77 \pm 0.31$ & \\
\hline Caprine & 4 rings & $1.98 \pm 0.25$ & $0.001^{*}$ & $1.07 \pm 0.08$ & 0.455 & $2.35 \pm 0.56$ & 1.000 & $1.20 \pm 0.10$ & 0.892 & $1.65 \pm 0.05$ & 0.618 \\
\hline
\end{tabular}

${ }^{*} \mathrm{P}<0.05$. A-P, anterior-posterior.

Table S2 One-way ANOVA of elastic modulus and tensile strength of tracheas

\begin{tabular}{|c|c|c|c|c|c|c|c|c|c|c|}
\hline Species & Outcome & Variable & Level & Mean \pm SD & SE & $\mathrm{F}$ test & $P$ value & \multicolumn{3}{|c|}{ LSD } \\
\hline \multirow[t]{5}{*}{ Porcine } & Elastic modulus ( $\mathrm{kPa})$ & Ring number & 4 & $594.12 \pm 156.35$ & 68.55 & 3.466 & 0.065 & 0.252 & 0.179 & $0.022^{*}$ \\
\hline & & & 6 & $883.70 \pm 437.39$ & 195.61 & & & & & \\
\hline & & & 8 & $1190.48 \pm 363.68$ & 162.64 & & & & & \\
\hline & & & 6 & $422.67 \pm 155.92$ & 69.73 & & & & & \\
\hline & & & 8 & $437.63 \pm 191.41$ & 85.60 & & & & & \\
\hline \multirow[t]{4}{*}{ Canine } & Elastic modulus $(\mathrm{kPa})$ & Ring number & 4 & $577.23 \pm 313.45$ & 180.97 & 5.833 & $0.039^{*}$ & $0.026^{\star}$ & 0.976 & $0.025^{\star}$ \\
\hline & & & 6 & $2550.67 \pm 1247.68$ & 720.35 & & & & & \\
\hline & & & 6 & $625.99 \pm 107.67$ & 62.16 & & & & & \\
\hline & & & 8 & $808.38 \pm 223.48$ & 129.03 & & & & & \\
\hline \multirow[t]{6}{*}{ Caprine } & Elastic modulus $(\mathrm{kPa})$ & Ring Number & 4 & $654.73 \pm 373.82$ & 215.83 & 14.295 & $0.005^{\star}$ & $0.039^{\star}$ & $0.034^{*}$ & $0.002^{*}$ \\
\hline & & & 6 & $1202.47 \pm 187.93$ & 108.5 & & & & & \\
\hline & & & 8 & $1771.27 \pm 145.54$ & 84.03 & & & & & \\
\hline & Tensile strength (kPa) & Ring Number & 4 & $358.41 \pm 127.74$ & 73.75 & 0.687 & 0.539 & 0.928 & 0.372 & 0.33 \\
\hline & & & 6 & $366.21 \pm 111.16$ & 64.18 & & & & & \\
\hline & & & 8 & $445.76 \pm 44.00$ & 25.40 & & & & & \\
\hline
\end{tabular}

${ }^{*} \mathrm{P}<0.05, \mathrm{SD}$, standard deviation; SE, standard error; LSD, least-significant difference. 
Table S3 One-way ANOVA of A-P and lateral L@50\%D of animal tracheas

\begin{tabular}{|c|c|c|c|c|c|c|c|c|c|c|}
\hline \multirow{2}{*}{ Species } & \multirow{2}{*}{ Outcome } & \multirow{2}{*}{ Variable } & \multirow{2}{*}{ Level } & \multirow{2}{*}{ Mean \pm SD } & \multirow{2}{*}{$\mathrm{SE}$} & \multirow{2}{*}{$\mathrm{F}$ test } & \multirow{2}{*}{$\mathrm{P}$ value } & \multicolumn{3}{|c|}{ LSD } \\
\hline & & & & & & & & 4,6 & 6,8 & 4,8 \\
\hline \multirow[t]{5}{*}{ Porcine } & A-P L@50\%D (N) & Ring Number & 4 & $4.86 \pm 1.20$ & 0.54 & 17.057 & $<0.001 *$ & 0.246 & $0.001 *$ & $<0.001^{*}$ \\
\hline & & & 6 & $5.53 \pm 0.43$ & 0.19 & & & & & \\
\hline & & & 8 & $7.94 \pm 0.82$ & 0.37 & & & & & \\
\hline & & & 6 & $7.39 \pm 0.61$ & 0.27 & & & & & \\
\hline & & & 8 & $8.75 \pm 0.82$ & 0.37 & & & & & \\
\hline \multirow[t]{4}{*}{ Canine } & A-P L@ @50\%D (N) & Ring Number & 4 & $4.35 \pm 0.05$ & 0.03 & 1478.796 & $<0.001 *$ & $<0.001 *$ & $0.002 *$ & $<0.001^{*}$ \\
\hline & & & 6 & $6.83 \pm 0.08$ & 0.05 & & & & & \\
\hline & & & 6 & $8.42 \pm 3.29$ & 1.90 & & & & & \\
\hline & & & 8 & $14.55 \pm 2.29$ & 1.32 & & & & & \\
\hline \multirow[t]{6}{*}{ Caprine } & A-P L@50\%D (N) & Ring Number & 4 & $4.73 \pm 0.20$ & 0.12 & 23.696 & $0.001 *$ & $0.022 *$ & $0.009^{*}$ & $<0.001 *$ \\
\hline & & & 6 & $5.38 \pm 0.10$ & 0.057 & & & & & \\
\hline & & & 8 & $6.18 \pm 0.38$ & 0.22 & & & & & \\
\hline & Lateral L@50\%D (N) & Ring Number & 4 & $8.10 \pm 1.87$ & 1.08 & 9.118 & $0.015^{*}$ & 0.068 & 0.087 & $0.005^{*}$ \\
\hline & & & 6 & $11.65 \pm 2.75$ & 1.58 & & & & & \\
\hline & & & 8 & $11.12 \pm 0.40$ & 0.38 & & & & & \\
\hline
\end{tabular}

${ }^{*} \mathrm{P}<0.05$. A-P, anterior-posterior; L@50\%D, load at the displacement reaches the 50\% original length of trachea; SD, standard deviation; $\mathrm{SE}$, standard error; LSD, least-significant difference. 